\title{
Orientação profissional na educação básica como política pública no Brasil
}

\author{
Lucy Leal Melo-Silva ${ }^{1}$ \\ Universidade de São Paulo, Ribeirão Preto-SP, Brasil \\ Izildinha Maria da Silva Munhoz \\ Universidade de São Paulo, Ribeirão Preto-SP, Brasil \\ Mara de Souza Leal \\ Universidade de São Paulo, Ribeirão Preto-SP, Brasil
}

\section{Resumo}

As políticas públicas constituem o foco deste estudo, objetivando identificar, sistematizar e analisar a legislação brasileira acerca da inserção da prática da Orientação Profissional no sistema educacional brasileiro. Constituíram fonte de dados os sites oficiais do Governo brasileiro e do Congresso Nacional. A sistematização dos dados foi organizada em dois eixos: as políticas públicas e as ações em Orientação Profissional em seus marcos históricos e legais; e as proposições legislativas no período de 2016 a 2018. Os resultados mostram que a legislação, historicamente, registra o interesse pela Orientação Profissional, ainda que não tenha sido universal e sequencial. Proposições foram feitas desconectadas dos avanços científicos. Na última proposição analisada, porém, já se observa alguma sintonia com a produção de conhecimento.

Palavras-chave: orientação profissional, orientação vocacional, política pública, leis

\section{Abstract: Professional guidance in elementary school as public policy in Brazil}

Public policies are the focus of this study, aiming to identify, systematize and analyze Brazilian legislation on the insertion of the professional guidance practice in the Brazilian educational system. The official websites of the Brazilian Government and the National Congress were taken as data source. The systematization of the data was organized in two axes: public policies and actions in Professional Guidance in its historical and legal frameworks; and legislative proposals in the period from 2016 to 2018. The results show that legislation historically registers interest in Professional Guidance, although it has not been universal and sequential. Propositions were made disconnected from scientific advances. In the last proposition analyzed, however, some harmony with the production of knowledge is already observed.

Keywords: professional orientation, vocational guidance, public policy, laws

\section{Resumen: Orientación profesional en la educación básica como política pública en Brasil}

Las políticas públicas constituyen el foco de este estudio, con el objetivo de identificar, sistematizar y analizar la legislación brasileña acerca de la inserción de la práctica de la Orientación Profesional en el sistema educativo brasileño. Constituyeron fuente de datos los sitios oficiales del Gobierno brasileño y del Congreso Nacional. La sistematización de los datos fue organizada en dos ejes: las políticas públicas y las acciones de Orientación Profesional en sus marcos históricos y legales; y las proposiciones legislativas en el período de 2016 a 2018. Los resultados muestran que la legislación, históricamente, refleja el interés hacia la Orientación Profesional, aunque no haya sido universal y secuencial. Las propuestas se elaboraron sin conexión con los avances científicos. En la última propuesta analizada, sin embargo, ya se observa alguna sintonía con la producción del conocimiento. Palabras clave: orientación profesional, orientación vocacional, política pública, leyes.

\footnotetext{
1 Endereço para correspondência: Faculdade de Filosofia, Ciências e Letras de Ribeirão Preto (FFCLRP/USP)
} Av. Bandeirantes, 3900, Bloco 5, sala 21 - CEP: 14040-901 - Ribeirão Preto/SP - Brasil 
Este estudo focaliza a política pública, enquanto conjunto de disposições que traduzem a orientação política do Estado, voltada para a Orientação Profissional em contextos educativos no Brasil. A necessidade de adoção de políticas públicas indutoras de ações no contexto educacional, que visem preparar os jovens para a vida profissional, incluindo o desenvolvimento de habilidades necessárias ao papel de trabalhador, a escolha da profissão e a inserção no mundo do trabalho, tem sido defendida com maior vigor desde o século passado por entidades internacionais. Dentre elas pode-se citar a Organização para a Cooperação e Desenvolvimento Econômico das Comunidades Europeias (OCDE), a International Association for Educational and Vocational Guidance (IAEVG) e o The Internacional Centre for Career Development and Public Policy (ICCDPP).

No cenário nacional, a Associação Brasileira de Orientação Profissional (ABOP), desde 1993, empreende ações para aglutinar pesquisadores e profissionais, assim como têm realizado esforços no sentido de incentivar a política pública para a inserção de atividades que promovam o desenvolvimento da carreira em diferentes contextos e cenários, com muitos desafios em um país de dimensão continental. Assim, o campo da Orientação Profissional, com seus arcabouços teóricos, tem procurado dar sustentação às práticas de intervenção em diferentes contextos e estágios do ciclo vital no sentido de ajudar as pessoas a escolherem, se prepararem e se desenvolverem em papéis profissionais, na perspectiva do desenvolvimento econômico "sustentável com mais e melhores empregos, maior coesão social e respeito ao meio ambiente" (McCarthy, 2009, p. 103).

Desde seus primórdios, no início do século passado, a área da Orientação Profissional tem passado por mudanças significativas em relação aos paradigmas teóricos buscando dar respostas às demandas decorrentes das transformações no mundo do trabalho. Os termos utilizados para se referir à área ilustram bem essas mudanças como aponta Ribeiro (2011). Durante a primeira metade do século XX, o termo utilizado "Orientação Vocacional", remetia à existência de uma vocação como tendência ou inclinação para um estado ou profissão e como aptidão natural, talento, como algo a ser descoberto por um orientador. Foram valorizadas as técnicas de avaliação psicológica para a identificação dos interesses, aptidões e traços de personalidade, dando origem ao termo "testes vocacionais". A demanda-chave naquela época era a de ajudar o indivíduo em seu processo de ajustamento vocacional/ocupacional (Ribeiro, 2011). A carreira no contexto do trabalho da época referia-se a um conjunto de cargos ou funções a serem assumidos em uma hierarquia estável e previsível. Gradativamente, junto com o termo Orientação Vocacional começa a ser utilizado o termo Orientação Profissional, enquanto prática voltada para ajudar na escolha, preparação ou exercício de uma profissão que requer formação.

No início dos anos 50, surgem as abordagens desenvolvimentistas, que "evidenciam a importância do autoconhecimento e dirigem as suas concepções para a compreensão do desenvolvimento e das mudanças que o comportamento na carreira vai tendo ao longo do tempo" (Duarte, 2013, p. 7). A orientação assume uma perspectiva de orientação ao longo da vida ressaltando o papel do autoconceito e da tomada de decisão da infância à aposentadoria. De acordo com esse enfoque, passa a se denominar Orientação de Carreira (Career Guidance), nos Estados Unidos e Orientação Escolar e Profissional, na Europa (Duarte, 2013).

As mudanças ocorridas no mundo, sob o impacto das novas tecnologias e da globalização dos mercados, desde o final do século XX, têm exigido cada vez mais teorias e práticas para responder aos inúmeros desafios da contemporaneidade em relação às intervenções em Orientação. O contexto do trabalho hoje apresenta-se instável e imprevisível, cabendo ao indivíduo a responsabilidade pela sua carreira ou de orientar-se para usar a expressão de Guichard (2012). Em consonância com este contexto, outra linha evolutiva revela-se: as teorias de construção da carreira e o Paradigma Life Design (Savickas et al, 2010). O pressuposto é que os indivíduos constroem suas próprias identidades de trabalho, em um processo contínuo, que se inicia na infância, tendo como base um processo reflexivo que relaciona mudança social e pessoal, indivíduo e contextos. Assim, carreiras não são reveladas, mas construídas na interação do indivíduo com os contextos. Segundo os autores supracitados, a intervenção segundo este modelo é melhor descrita como uma Orientação para a Construção da Carreira.

A respeito da nomenclatura na área, pode-se perceber que, ao longo da evolução, a intervenção em Orientação recebeu várias denominações: Orientação Vocacional, Orientação Profissional, Orientação para o Desenvolvimento Vocacional, Orientação para a Carreira, Orientação para a Construção da Carreira, que foram usadas em função dos respaldos teóricos que as embasam e são usadas pelos autores de acordo com os paradigmas adotados. No Brasil, segundo Ribeiro (2011) o termo Orientação Profissional é o que melhor satisfaz as necessidades contemporâneas e representa a história da área no Brasil. Assim, a Orientação Profissional, enquanto intervenção, é definida como um processo que deve ser realizado ao longo da vida, que pode ter como finalidade trabalhar a escolha, a inserção profissional ou o desenvolvimento de um projeto de carreira, com vistas ao desenvolvimento pessoal e social do sujeito. Esse processo pode ser realizado em diferentes contextos, de forma individual ou coletiva, por um profissional qualificado na área, considerando-se as questões sociodemográficas (Ribeiro, 
2011). Assim, nesta perspectiva, adota-se esse termo neste estudo.

Para além dos contextos individuais, as práticas de Orientação Profissional se inserem em um contexto mais amplo que envolve questões relativas à política, economia, cultura, etnia e localização geográfica e estão intimamente relacionadas a essas questões. McCarthy (2009), no contexto da ICCDPP, reforça essa dimensão política da Orientação Profissional ao considerar que as intervenções de carreira são processos sociopolíticos e devem ser planejadas para cumprir metas nacionais e implementadas por meio de políticas públicas nas áreas de educação, formação e emprego.

Em função da importância da efetivação de práticas de Orientação Profissional para o desenvolvimento dos indivíduos e das nações, no início do século XXI, foram realizados estudos com o objetivo de identificar tais práticas, avaliá-las e estabelecer diretrizes que norteassem a elaboração de políticas públicas, em países da Comunidade Europeia, da América do Norte (principalmente Estados Unidos e Canadá), do Sudeste da Ásia e de países em desenvolvimento. Munhoz (2010) apresenta os resultados dos estudos realizados e conclui que é possível observar um movimento em países da Europa, nos Estados Unidos, Austrália, Canadá e outros no sentido de implementar as políticas públicas de Orientação Profissional aumentando a população atendida bem como facilitando o acesso a tais serviços em diferentes momentos da vida das pessoas.

McCarthy (2009), no cenário mundial, destaca que, de modo geral, as investigações sobre as políticas públicas para a Orientação Profissional estavam mal definidas e pouco integradas. Assim, o referido autor faz recomendações sobre a direção que os diferentes países precisariam seguir para reforçar a Orientação Profissional nas políticas nacionais de aprendizagem ao longo da vida. Dentre elas: (a) a ampliação do acesso a serviços de orientação para a carreira ao longo da vida de alta qualidade para todas as camadas da população; (b) a necessidade de melhorar coordenação e cooperação entre os ministérios e serviços voltados à educação, saúde e trabalho; (c) a formação e qualificação de profissionais de orientação; (d) o desenvolvimento de uma base de dados para apoiar políticas de orientação para a carreira e, (e) o estabelecimento de "mecanismos nacionais e regionais para envolver todas as partes interessadas ministérios, parceiros sociais, sociedade civil (como pais, jovens, profissionais) no desenvolvimento de políticas públicas e sistemas de orientação" (McCarthy, 2009, p. 105).

McCarthy (2009) defende a necessidade de se estabelecer políticas públicas voltadas à educação, formação e emprego de jovens que tenham como pressuposto a perspectiva da aprendizagem ao longo da vida, no sentido de que os potenciais aprendizes sejam apoiados por serviços de Orientação Profissional que devem iniciar nos primeiros anos escolares e se estender ao longo da carreira, com objetivos diferentes a cada momento. É nessa perspectiva que se compreende a Orientação Profissional nesse estudo, como um campo com diferentes possibilidades de intervenção.

No contexto educativo, uma modalidade de intervenção recomendada internacionalmente é a Educação para a Carreira, cujo princípio básico é a articulação entre educação, trabalho e carreira. Seus idealizadores, Sidney Marland e Kenneth Hoyt, defenderam um projeto de reforma educacional na década de 70, nos Estados Unidos, que permitisse à educação pública preparar melhor os alunos para enfrentar as mudanças da sociedade pós -industrial, principalmente no mercado de trabalho e na concepção de carreira. A inserção de temas relativos a trabalho em contextos de aprendizagem deveria ocorrer desde as séries iniciais da escolaridade (Hoyt, 2005). A proposta tinha como foco o desenvolvimento de conhecimentos, habilidades e atitudes para ajudar os alunos a construírem projetos de vida e de carreira, tomarem decisões adequadas sobre opções de estudos e/ou trabalho e capacitá-los a participar efetivamente de uma vida profissional (Munhoz, 2010). Embora a implantação da Educação para a Carreira, tal como defendida por Hoyt e Marland, não tenha obtido o sucesso que seus idealizadores esperavam, pois o projeto de reforma educativa foi rejeitado em 1982, o movimento plantou as sementes de um modelo que vem sendo adotado por outros países, com diferentes formas de execução, mas sempre com um enfoque desenvolvimentista e educacional (Munhoz, 2010).

Nesse sentido, Hoyt (1995) reconsidera o conceito de Educação para a Carreira e propõe que na educação básica as atividades aconteçam em quatro fases: (a) consciência sobre carreiras, na educação infantil e ensino fundamental; (b) exploração de carreiras, nos anos finais do ensino fundamental, (c) tomada de decisão sobre a própria carreira, no ensino médio e, (d) desenvolvimento de habilidades para lidar com as transições que ocorrem durante a vida escolar, como por ex.: mudanças de ciclos ou modalidades de ensino, mudanças nos papéis a serem desempenhados da escola para o trabalho.

As atividades pertinentes à Educação para a Carreira poderiam ser contempladas com a oferta de serviços de Orientação Profissional em contextos educativos voltados à educação infantil e ao ensino fundamental. Nesses níveis de ensino, o foco é a inserção nas atividades de aprendizagem de temas relativos aos estudos e ao trabalho com o objetivo de desenvolver as competências necessárias a um trabalhador. As atividades voltadas para a escolha, envolvendo o autoconhecimento, informação sobre as opções de estudo e trabalho e tomada de decisão, aconteceriam a partir do nono ano. Considera-se aqui que, mais do que competir, a Educação para a Carreira e a Orientação Profissional no contexto educativo, são complementares. 
Mas, para que propostas como a Educação para a Carreira ou a Orientação Profissional, sejam introduzidas no contexto escolar, há necessidade de políticas públicas que garantam sua viabilidade. Só desta forma, poder-se-á garantir que todos os jovens tenham acesso a tais serviços, fato que não acontece no contexto brasileiro, onde apenas uma pequena parcela tem acesso a serviços desta natureza (Melo-Silva, Lassance, \& Soares, 2004; Munhoz, 2010).

Nesse sentido, a questão a que se propõe este estudo é conhecer como os legisladores no Brasil têm tratado a necessidade de se inserir atividades de Orientação Profissional na Educação Básica. Assim, este estudo foi delineado com o objetivo de identificar, sistematizar e analisar a legislação brasileira, as leis e as proposições legislativas, acerca da inserção da prática da Orientação Profissional no sistema educacional brasileiro público e privado.

\section{Método}

A fim de alcançar o objetivo, foi realizada uma pesquisa documental organizada em duas partes. A primeira parte deste estudo trata da busca da legislação histórica e atual da educação brasileira no período compreendido entre 1924 e 2018, no sentido de identificar propostas de Orientação Profissional inseridas (ou não) no contexto escolar. A consulta às leis históricas e atuais foi realizada nos sites da Câmara dos Deputados (http://www2.camara. leg.br/atividade-legislativa/legislacao), do Senado (http:// www25.senado.leg.br/web/atividade/legislacao) e do Observatório do PNE (http://www.observatoriodopne. org.br/pne/linha-do-tempo). Dois estudos foram relevantes nesta busca e análise: o de Pimenta (1981) e o de Munhoz (2010). A segunda parte consiste em um mapeamento da situação de proposições legislativas federais sobre a área em estudo, delimitada ao período entre 2007 e 2018. Para tanto, procedeu-se a uma pesquisa nos sites da Câmara Federal (http://www.camara.leg.br/buscaProposicoesWeb/pesquisaSimplificada) e do Senado (http:// www25.senado.leg.br/web/atividade/materias) utilizando como descritores os termos: "Orientação Profissional", "Orientação Vocacional", "Teste Vocacional", "Preparação para o Trabalho" e "Educação para a Carreira". Os três primeiros termos foram definidos para a busca por serem os mais utilizados pelas pessoas, em geral, e os legisladores. O termo "preparação para o trabalho" foi inserido na busca por estar presente na legislação mais recente. E, "educação para a carreira" por servir um conceito internacional para práticas no contexto da educação, entendimento que pode ser de paradigma para a política pública ou de modelo de intervenção no contexto escolar.

Nas proposições legislativas encontradas buscou-se identificar as categorias e os conceitos utilizados para se referir à intervenção, ao público-alvo, à esfera administrativa da escola, à natureza da atividade e aos profissionais encarregados. Os conceitos a serem identificados referem-se ao descritor utilizado nas leis e projetos de leis encontrados para se referir às práticas de intervenção. O público-alvo diz respeito à população a quem se dirige a lei ou projeto de lei, com destaque para a série escolar quando é mencionada. A esfera administrativa da escola considera a natureza: pública ou privada, municipal, estadual ou federal, a qual a proposição é direcionada. E, a categoria natureza da atividade classifica os Projetos de Lei quanto à modalidade de serviço oferecido (extracurricular, interdisciplinar, obrigatório, facultativo ou infusivo) e o tipo de atividade (seminários, palestras, eventos, semana temática, entrevista, programas, testes e outras técnicas).

Após a seleção e leitura dos materiais coletados, a sistematização dos dados foi organizada por meio de dois eixos temáticos, descritos a seguir.

a) Políticas públicas e ações em Orientação Profissional no contexto escolar brasileiro: marcos históricos e legais.

b) Orientação Profissional no contexto escolar brasileiro: perspectivas nas proposições legislativas do Congresso Nacional.

\section{Resultados e Discussão}

Eixo temático 1. Políticas públicas e ações em Orientação Profissional no contexto escolar brasileiro: marcos históricos e legais

Historicamente, a Orientação Profissional no Brasil surgiu na década de 1920 vinculada ao sistema de ensino, na vertente da Educação Profissional, com o objetivo de selecionar e orientar jovens para cursos profissionalizantes. Essa experiência se multiplicou para vários pontos do país, com grande número de estudos e produção científica. No plano das legislações, a inserção da Orientação Profissional no contexto escolar brasileiro é sugerida pela primeira vez em 1931, na Reforma Francisco Campos e consolidada nas Leis Orgânicas de Ensino. Essas leis, promulgadas entre 1942 e 1946 reformularam todo o sistema de ensino no Brasil e introduziram a Orientação Profissional no contexto escolar como atribuição do orientador educacional (Brasil, 1942a, b; 1943; 1946a, b).

Durante esse período, foram criados o Serviço Nacional de Aprendizagem Industrial (SENAI) e o Serviço Nacional de Aprendizagem Comercial (SENAC), que contribuíram para a expansão de Serviços de Orientação Profissional no Brasil. Em consonância com o que acontecia no panorama internacional, o orientador profissional atuava no enfoque psicométrico, utilizando instrumentos 
para avaliar as características do aluno e adequá-las às exigências do curso ou profissão (Pimenta, 1981).

A Lei de Diretrizes e Bases da Educação Nacional de 1961 - LDB 4024/61 - introduziu oficialmente o "Aconselhamento Vocacional" nas escolas, sob a coordenação do orientador educacional. Assim, ao orientador "educativo e vocacional" caberiam as funções de orientação escolar, psicológica, profissional, da saúde, recreativa e familiar. $\mathrm{Na}$ Orientação Profissional, sua função seria identificar as aptidões individuais de todos os alunos, utilizando-se de todos os elementos da escola para desenvolver esse trabalho (Brasil, 1961).

A partir da LDB/61 a atuação dos orientadores na escola deveria ser realizada no Ensino Médio, em consonância com o modelo do aconselhamento, por meio da avaliação das características pessoais utilizando, para isso, instrumentos de avaliação psicológica. Entretanto, quando em 1964, a profissão de psicólogo foi regulamentada e os testes passam a ser de uso exclusivo destes profissionais, os pedagogos nas escolas ficam sem instrumentos de avaliação para a Orientação Profissional e, gradativamente, passam a se dedicar mais aos aspectos de adaptação e ajustamento dos alunos (Pimenta, 1981).

Posteriormente, a Lei de Diretrizes e Bases da Educação Nacional de 1971 - LDB 5692/71- instituiu o segundo grau como profissionalizante, com o objetivo de oferecer uma formação técnica básica a todos os alunos do Ensino Médio, eliminando o dualismo entre escola de $2^{\circ}$ grau e escola técnica (Brasil, 1971). A referida lei, tornou obrigatória a Orientação Educacional nas escolas, com a função de realizar o Aconselhamento Vocacional e "possibilitar assistência aos alunos na maximização de seus recursos pessoais para que façam opção profissional conforme as necessidades do mercado de trabalho", como apontou Pimenta (1981, p. 99) no contexto de uma publicação na qual critica a Orientação Profissional tradicional.

A proposta de implementação compulsória da profissionalização do Ensino Médio foi alterada pela Lei n. ${ }^{\circ}$ 7044/82 (Brasil, 1982), que tornou facultativas a qualificação e habilitação profissional de nível técnico (Nascimento, 2007). Embora não tenha revogado a obrigatoriedade da Orientação Vocacional e/ou Profissional nas escolas, este fato, aliado às dificuldades na realização da orientação, fizeram com que a atividade gradativamente deixasse de ser realizada. Outra questão que contribuiu para reduzir a oferta dos serviços de Orientação Profissional nas escolas, foram as críticas, na década de 80 , em relação à excessiva ênfase nos processos psicológicos da escolha profissional, em detrimento de outras variáveis igualmente importantes, como as questões socioeconômicas e culturais (Ferretti, 1997; Pimenta, 1981).

Diante desta situação, tanto nas escolas públicas como nas escolas particulares, a Orientação Profissional, como prática intencional e sistematizada, seja como aconselhamento vocacional ou como ações voltadas a uma preparação básica para o trabalho, foi gradativamente desaparecendo das escolas públicas. Algumas ações pontuais ficaram restritas a palestras de profissionais e eventuais atividades para as séries terminais do ensino médio, como visitas promovidas por instituições para divulgação de seus cursos (Melo-Silva, Lassance, \& Soares, 2004).

A partir da década de 1990 até os dias atuais, a Lei de Diretrizes e Bases da Educação em vigor é a LDB 9.394/96 (Brasil, 1996), promulgada em 20 de dezembro de 1996 e reformulada muitas vezes até o ano de 2018. Nenhuma das reformulações fez menção a questões relativas à Orientação Profissional, apesar da ênfase em vários artigos sobre a necessidade de a educação básica relacionar estudos ao trabalho e de oferecer, mais especificamente no ensino médio, uma preparação básica para o futuro que permita ao jovem adaptar-se com flexibilidade a novas condições de ocupação e ao aperfeiçoamento posteriores na construção da sua vida e carreira.

As mudanças realizadas na LDB/96 pela Lei 13.415/2017 (Brasil, 2017), analisadas ao final desta seção, reafirmam os discursos sobre a necessidade da preparação para o trabalho, de a escola fornecer oportunidade aos alunos de participarem de atividades que os auxiliem a construírem seus projetos de vida e, consonante com esse projeto, realizar escolhas entre percursos formativos ao longo do ensino médio e/ou dar continuidade aos estudos no ensino superior. No entanto, efetivamente, não há diretriz para a implantação de serviços especializados de apoio aos alunos para as decisões de carreira.

Para além das Leis de Diretrizes e Bases da Educação, também não foram encontradas referências sobre a inserção de práticas de Orientação Profissional no contexto escolar em outros documentos relevantes ao escopo deste estudo como, por exemplo, o Decreto 5.154/2004 (Brasil, 2004) e a Lei 11.741/ 2008 (Brasil, 2008) sobre a relação entre o ensino médio e a educação profissional de nível médio. Essas leis postulam a possibilidade de integração entre o ensino médio e o ensino profissional, podendo oferecer uma qualificação profissional, mas nenhum apoio ao aluno é mencionado no sentido de ajudá -lo a decidir qual percurso fazer.

As Diretrizes Curriculares Nacionais Gerais da Educação Básica de 2013, embora proponham uma reorganização curricular "para que os jovens tenham oportunidades de escolher o percurso formativo que mais atenda seus interesses, suas necessidades e suas aspirações" (Brasil, 2013, p. 40), em nenhum momento postula sobre ações, atividades ou profissionais encarregados, para auxiliar os alunos no processo de decisão sobre estudos. Outros documentos referentes ao ensino médio também são omissos.

O atual Plano Nacional de Educação (PNE), previsto no artigo 214 da Constituição Federal, foi promulgado em 2014 com vigência de dez anos (Brasil, 2014) e estabelece 
diretrizes, metas e estratégias de concretização no campo da Educação. O referido PNE estabelece vinte metas a serem alcançadas no período entre 2014 e 2024 , referentes a vários setores e problemas pertinentes ao sistema educacional brasileiro. Esse documento também omite qualquer referência à oferta de serviços de Orientação Profissional, apesar de tratar de questões pertinentes à sua necessidade, como a previsão de o aluno escolher percursos formativos no ensino médio e de aumento significativo da carga horária de Educação Profissional que articule formação básica e preparação para o mundo do trabalho.

A lei 13.415/2017 (Brasil, 2017) que reformulou a LDB 9394/96 promoveu uma série de mudanças na educação básica, especialmente no ensino médio. A aprovação da Lei 13.415/2017 gerou muita polêmica em função de ter sido convertida em lei a partir de uma medida provisória (MP 746/2016). Segundo os críticos, a medida não foi debatida pela sociedade nem pelo poder legislativo. Entretanto, a MP 746/2016 incorporou a maioria das propostas do Projeto de Lei 6840/2013 (ver Apêndice 1) de autoria da Comissão Especial destinada a promover Estudos e Proposições para a Reformulação do Ensino Médio (CEENSI) da Câmara dos Deputados que está em discussão desde 27 de novembro de 2013.

Dentre as modificações que a Lei 13.415/2017 inseriu no ensino médio, e que deverão ser implantadas a partir de 2019, estão: (a) aumento da carga horária mínima de oitocentas para mil e quatrocentas horas anuais; (b) implantação gradual do ensino integral; (c) agrupamento dos conteúdos em cinco áreas do conhecimento: Linguagens, Matemática, Ciências da Natureza, Ciências Humanas e Sociais Aplicadas e Educação Profissional; (d) necessidade de que os alunos no ensino médio escolham uma das quatro áreas do conhecimento ou a formação técnica e profissional, de acordo com seus interesses e necessidades (Brasil, 2017). Segundo essa lei o currículo do ensino médio será composto pela Base Nacional Comum Curricular (BNCC) e por itinerários formativos específicos com ênfase nas quatro áreas de conhecimento ou de atuação profissional mencionadas anteriormente. A organização das áreas e das respectivas competências e habilidades em percursos formativos será feita de acordo com critérios estabelecidos em cada sistema de ensino, sendo possibilitado ao aluno concluinte do ensino médio cursar mais de um itinerário formativo.

De acordo com a Lei 13.415/2017 "as escolas deverão orientar os alunos no processo de escolha das áreas de conhecimento ou de atuação profissional" (Brasil, 2017, Art. $\left.4^{\circ}, \S 12\right)$. Entretanto, não menciona quem ou como essa orientação poderá acontecer. A BNCC para a educação básica, ainda em processo de discussão, está disponível no site http://basenacionalcomum.mec.gov.br/.

A BNCC para o ensino médio foi entregue ao Conselho Nacional de Educação em 04 de abril de 2018 e aguarda a aprovação pelo Conselho Nacional de Educação
(CNE). O documento ressalta "a importância de que, ao longo da sua formação os estudantes do ensino médio sejam apoiados na construção de seu projeto de vida, tendo como ponto de partida o reconhecimento de seus interesses, potenciais e vocações, bem como de suas possibilidades e aspirações enquanto pessoa, profissional e cidadão" (Brasil, 2016b, p. 493). Mais uma vez, nenhuma referência é feita sobre a disponibilização de serviços/ pessoas, que possam contribuir para que esse apoio seja de fato oferecido. Assim, a Orientação Profissional continua ausente como prática sistematizada no sistema de ensino no Brasil.

Em resumo, os resultados desta análise da legislação brasileira no período correspondente a 1924 e 2018 permitiram identificar que, desde 1924, marco inicial das primeiras atividades no Brasil, até as leis de ensino compreendidas entre 1930 e 1971, as políticas de Orientação Profissional se posicionavam no sentido de se realizar a Orientação Vocacional ou Profissional para alunos do ensino médio, na vertente do Aconselhamento Vocacional e voltado para a escolha de um curso profissionalizante (técnico ou superior). Entretanto, a partir da LDB 7044/82 não se encontra nos documentos oficiais nenhuma menção a atividades de Orientação Profissional, seja na atual LDB 9394/96, com todas as suas modificações (inclusive as promovidas pela Lei 13.415/2017, referentes a escolha de percursos formativos) ou nas metas e estratégias do atual Plano Nacional de Educação 2014/2024.

Desta forma, os textos legais em vigência continuam não referendando a obrigatoriedade da oferta de serviços de Orientação Profissional que possam promover oportunidades para o desenvolvimento de habilidades para a tomada de decisão e de competências básicas para a construção da carreira e a participação no mundo do trabalho. A Lei 13.415/2017 (Brasil, 2017) possibilita aos estudantes a oportunidade de realizar um curso técnico profissionalizante, favorecendo a inserção mais rápida no mercado de trabalho para aqueles que não aspiram ao ensino superior, mas, por outro lado, pode limitar as possiblidades de progressão, via estudos, na construção da carreira. Refletir e escolher o melhor itinerário formativo, pela legislação vigente, parece depender de um movimento individual, ficando a escola sem referência legal de como estes serviços de orientação serão oferecidos e por quem serão realizados.

A partir das considerações de que o desenvolvimento da carreira é um processo que se inicia nos primeiros anos escolares e se estende ao longo da vida, em um contexto de aprendizagem contínua; de que as primeiras experiências escolares constituem as bases do desenvolvimento de muitas competências necessárias a um desempenho profissional que permita à pessoa o pleno uso de suas potencialidades e aspirações; constata-se a necessidade de oferta de atividades sistematizadas e contínuas que promovam o desenvolvimento de competências-chave para a 
carreira no contexto educacional. Nesse sentido, há necessidade de propostas e estratégias que sustentem ações no contexto escolar, seja de Orientação Profissional, seja de Educação para a Carreira, destinadas a ajudar os jovens a se conhecerem, conhecerem a realidade do universo profissional, aprenderem a tomar decisões e se prepararem para a transição escola-trabalho. Partindo deste enfoque é que as proposições legislativas foram analisadas, e encontram-se descritas na seção subsequente.

Eixo temático 2. Orientação Profissional no contexto escolar brasileiro: perspectivas nas proposições legislativas do Congresso Nacional

Em relação às proposições legislativas, os resultados encontrados evidenciam que a oferta de serviços de Orientação Profissional tem sido objeto de propostas na esfera do legislativo federal, com evolução da forma como as atividades devem ser realizadas nas escolas. Todas as proposições citadas nesse artigo podem ser encontradas nos sítios de busca da Câmara dos Deputados e do Senado Federal. O Apêndice 1 mostra detalhadamente os sítios das proposições.

No âmbito do Congresso Nacional (Câmara dos Deputados e Senado) foram encontradas vinte proposições legislativas no período de 2007 a 2018. Destas, 17 referem-se a propostas da Câmara dos Deputados, sendo catorze Projetos de Lei (PLs), duas Indicações e uma proposta de Emenda para a Comissão (EMC). A Indicação é o documento legislativo que visa sugerir a outro poder que adote providências ou que uma ou mais Comissões se manifestem sobre determinado assunto. A Tabela 1 mostra o número de proposições legislativas contabilizadas nos sítios da Câmara Federal e do Senado.

No caso das indicações, uma delas sugere ao Ministério da Educação que inclua, obrigatoriamente, na grade extracurricular do terceiro ano do ensino médio, palestras relacionadas à Orientação Profissional (INC 495/2007) e outra ao Poder Executivo, para que "seja instituída oferta de Orientação Vocacional aos alunos do último ano do ensino médio" (INC 1696/2015). Em relação às emendas, a EMC 336/2011 refere-se a uma proposta de emenda apresentada à comissão especial destinada a proferir parecer ao PL 8035/2010 do poder executivo, sobre o Plano Nacional de Educação para o decênio 2011-2020. A referida proposta de emenda tinha como objetivo incluir no Plano Plurianual de Investimentos, no Orçamento da União e na Lei de Diretrizes Orçamentárias, no período 2011-2020, a “obrigatoriedade da destinação de recursos no Orçamento da União para subsidiar a Orientação Vocacional dos jovens brasileiros para o ensino médio, para a educação técnico-profissional e para a educação superior, presencial e à distância, bem assim para capacitação e avaliação de professores com esse objetivo". Essa proposta de emenda não foi incluída no texto final da Lei 13.005 de 2014, que institui o PNE, período 2014-2024, em substituição ao PNE 2011-2020 (Brasil, 2014).

Sobre os PLs, dos catorze encontrados na Câmara dos Deputados, onze (78,5\%) se referiam especificamente à Orientação Vocacional/ Profissional ou realização de testes vocacionais e três foram considerados de interesse (PL 838/ 2007, PL 3993/2008 e PL 4836/ 2009). O PL 838/ 2007 estabelece a obrigatoriedade da presença do orientador educacional nas instituições públicas de educação básica, considerando a "orientação socioprofissional" como uma das áreas de atuação desse profissional a serem realizadas no contexto escolar. O PL 3993/2008 propõe a inclusão no ensino fundamental de um "componente curricular dedicado ao desenvolvimento dos valores éticos e de cidadania". Sua inclusão neste estudo deve-se ao fato de que junto a ele se encontra apensado um projeto de interesse específico, o PL 562/2015, que propõe a obrigatoriedade da disciplina de Orientação Profissional, na grade escolar do Ensino Médio. O PL 4836/ 2009, por sua vez, dispõe sobre a obrigatoriedade de "publicação das pesquisas de trabalho e emprego, produzidas pelo Ministério do Trabalho e Emprego, nas escolas brasileiras".

Importante observar que o ano de 2015 foi o mais profícuo em proposições legislativas na Câmara dos Deputados com cinco projetos de lei e uma indicação. Os cinco PLs encontram-se apensados ao PL 5053/2016 que está aguardando parecer do relator na Comissão de Educação (CE). Ressalte-se ainda que o PL 5053/2016 tem como origem o Projeto de Lei do Senado - PLS 426/2015,

Tabela 1

Número de Proposições Legislativas

\begin{tabular}{lcccccc}
\hline \multirow{2}{*}{ TIPO DE PROPOSIÇÃO } & \multicolumn{2}{c}{ CÂMARA } & \multicolumn{2}{c}{ SENADO } & \multicolumn{2}{c}{ TOTAL } \\
\cline { 2 - 7 } & F & $\%$ & F & $\%$ & F & $\%$ \\
\hline - Indicação & 02 & 11,8 & -- & & 02 & 10,0 \\
- Proposta de Emenda & 01 & 5,9 & -- & & 01 & 5,0 \\
- Projetos de Leis específicos & 11 & 64,7 & 03 & 100,0 & 14 & 70,0 \\
- Projetos de Leis relacionados & 03 & 17,6 & -- & & 03 & 15,0 \\
TOTAL & 17 & 100,0 & 03 & 100,0 & 20 & 100,0 \\
\hline
\end{tabular}


aprovado em quinze de abril de 2016 e enviado à Câmara dos Deputados.

No Senado Federal os três projetos de lei encontrados foram aprimorados ao longo do tempo, sendo que o texto aprovado (PLS 426/2015) revela-se, em sua justificação, mais adequado ao contexto teórico-prático atual da área da Orientação Profissional do que os anteriores (PLS 187/2008 e PLS 228/2012), como poderá ser observado ao longo desta subseção.

Para descrever como as diferentes proposições discorrem sobre a oferta de atividades do domínio da Orientação Profissional foram analisadas as categorias: conceitos utilizados, público-alvo, esfera administrativa da escola, natureza da atividade e profissionais encarregados, apresentadas a seguir. A Tabela 2 apresenta os conceitos-chave explicitados nas proposições legislativas apresentadas pela Câmara dos Deputados e pelo Senado Federal.

Como se pode observar, no âmbito federal as denominações mais utilizadas foram Orientação Vocacional e Orientação Profissional, sendo que em algumas propostas foram citados, em seu objetivo básico ou nas justificativas, mais de um termo, (por ex.: PL 6068/2009, PL 6510/2013, PL 4209/2015 e PLS 426/2015). Os conceitos Educação para a Carreira e Preparação para o Trabalho não foram encontrados nos projetos de lei e leis analisados. Observou-se ainda que o termo "teste vocacional" tem sido cada vez menos utilizado nas proposições legislativas.

Nesse sentido, é importante ressaltar que, em relação à utilização de instrumentos de avaliação das pessoas e de seus atributos (o "teste vocacional" como é popularmente descrito) a literatura recomenda (Ambiel, 2010; Lamas, 2015) referir-se à avaliação psicológica, ou seja, de dimensões e atributos, tais como, interesses, maturidade para a escolha profissional, aptidões, habilidades, valores, personalidade, autoeficácia, competências de carreira, entre outras, uma vez que não existem testes vocacionais. Para políticas públicas universais, que visam atender a um número grande de estudantes, esse tipo de avaliação pode não ser factível, pois requer profissional especializado e o custo para aplicação em grandes grupos seria inviável nas escolas.
A avaliação de dimensões psicológicas é relevante e significativa em contextos individuais e em pequenos grupos. Além disso, tais avaliações são de uso exclusivo de psicólogos. Profissionais de diferentes categorias, com formação específica, poderão atuar com propostas mais abrangentes de Orientação Profissional ou de Educação para a Carreira e com o uso de instrumentos de medidas não privativos do psicólogo.

Além disso, nos últimos cinco anos, de doze proposições legislativas encontradas, apenas três propõem a obrigatoriedade da aplicação de "testes vocacionais", os demais se alternam entre o uso das nomenclaturas de Orientação Vocacional e Profissional. Em alguns desses documentos já se percebe uma fundamentação mais atualizada de acordo com o que recomendam a literatura e a prática da área.

Nesse sentido, há que se ressaltar as considerações feitas pelo relator Senador Donizeti Nogueira quando da análise do Projeto de Lei do Senado (PLS) 426/2015, aprovado em 2016, que se apresenta como a de maior sintonia com o momento atual do campo da Orientação Profissional. Embora utilize indiscriminadamente os termos Orientação Profissional e Orientação Vocacional, o relator faz uma discussão importante sobre os termos a serem utilizados, ao público a qual se destinam as ações e os tipos de serviços a serem oferecidos (estes dois últimos itens serão analisados a seguir). Em relação aos termos utilizados, o texto deixa claro que as possibilidades da Orientação Profissional não se restringem à aplicação de um "teste vocacional" (agora em sintonia com a produção do conhecimento), defendendo uma abordagem mais ampla, de um "serviço de orientação profissional" que se realize como um processo, no qual "o profissional especializado e o orientando discutem escolhas, mas o último é que é senhor dos próprios caminhos" (PLS 426/2015, p. 3).

Em relação ao alcance das ações no sistema de ensino, nas proposições legislativas encontradas no âmbito federal, a maior parte, tanto na Câmara $(57,1 \%)$ como no Senado (60\%) se refere ao ensino público, com proposições mencionando tanto o ensino público como o privado (14,3\% na Câmara e 12,5\% no Senado). Apenas

Tabela 2

Conceitos-chave mencionados nas proposições legislativas no âmbito Federal

\begin{tabular}{lcccccc}
\hline \multirow{2}{*}{ CONCEITO UTILIZADO } & \multicolumn{2}{c}{ CÂMARA } & \multicolumn{2}{c}{ SENADO } & \multicolumn{2}{c}{ TOTAL } \\
\cline { 2 - 7 } & $\mathrm{F}$ & $\%$ & $\mathrm{~F}$ & $\%$ & $\mathrm{~F}$ & $\%$ \\
\hline - Orientação Vocacional & 08 & 44,4 & 01 & 33,4 & 09 & 45,0 \\
- Orientação Profissional & 06 & 33,3 & 01 & 33,3 & 07 & 35,0 \\
- Teste Vocacional & 03 & 16,7 & 01 & 33,3 & 04 & 20,0 \\
- Orientação Socioprofissional & 01 & 5,6 & 0 & 0 & 0 & 0 \\
TOTAL & 18 & 100,0 & 03 & 100,0 & 20 & 100,0 \\
\hline
\end{tabular}


uma proposição não especificou a natureza da rede de ensino (3,8\%). Salienta-se que o Projeto de Lei do Senado - PLS 426/2015 propõe que o Serviço de Orientação Profissional seja ofertado de forma gratuita aos estudantes da rede pública e aos "beneficiários de bolsa integral na rede privada". O que, em tese, não torna obrigatória a oferta de Orientação Profissional nas escolas particulares para todos os alunos. Mas, neste estudo, defende-se a ideia de que a oferta de serviços de Orientação Profissional se estenda a todos os alunos, inclusive das escolas particulares, na medida em que estas, assim como as públicas, têm negligenciado "uma intervenção mais ampla, no sentido da educação voltada à construção da carreira, do projeto de vida e da capacidade de análise crítica da realidade social" (Valore \& Cavallet, 2012, p.355). A seguir, a Tabela 3 mostra os níveis de ensino e o público-alvo/ série que as proposições legislativas do Câmara Federal e Senado focalizam.

No que tange ao público-alvo segundo o nível de ensino, as propostas diferem, ora sendo muito abrangentes, ora muito restritivas. Assim, algumas propostas estabelecem as ações que deveriam ser aplicadas ao ensino médio, ao ensino técnico profissional, à educação de jovens e adultos e à educação superior, "presencial e a distância"; outras são bem mais restritas, estabelecendo a obrigatoriedade apenas à última série do ensino médio. Como se pode observar na Tabela 3, metade das propostas se destinaram ao ensino médio regular, subentendendo-se que as ações devam ocorrer desde as séries iniciais desta etapa. Entretanto, o último ano do ensino médio é citado em $15 \%$ das proposições legislativas, revelando a concepção de ajuda ao aluno no momento da escolha de um curso superior, reforçando a ideia de um trabalho voltado predominantemente para este fim.

Novamente, o Projeto de Lei 426/2015 do Senado Federal, traz mudança importante nesse âmbito, na medida em que propõe que o Serviço de Orientação Profissional seja oferecido na educação básica, a partir do último ano do ensino fundamental, "para fins de apoio à decisão sobre prosseguimento de estudos em curso técnico de nível médio e na educação superior" (PLS 426/2015, p. $5)$. Na justificativa o relator argumenta que se a profissionalização é possível a partir do ensino médio, torna-se necessária a oferta de Serviço de Orientação Profissional para aqueles que podem não querer (ou não poder) realizar um curso superior.

Desta forma, o PLS 426/2015 inova ao estender o escopo da Orientação Profissional para o ensino fundamental e permitir que se amplie também os objetivos para além da escolha de um curso superior ou profissionalizante. Considera-se esse avanço importante na medida em que garantir que as atividades de orientação se estendam ao ensino fundamental, abriria espaço para que atividades de Educação para a Carreira contribuíssem para que o aluno possa valorizar os diversos saberes e vivências culturais e se aproprie de conhecimentos e experiências que lhe "possibilitem entender as relações próprias do mundo do trabalho e fazer escolhas alinhadas ao exercício da cidadania e ao seu projeto de vida, liberdade, autonomia, consciência crítica e responsabilidade" (Brasil, 2018, p. 9). Quanto às modalidades de inserção e aos tipos de atividades da Orientação Profissional no contexto escolar, as proposições legislativas focalizam aspectos diferentes como mostra a Tabela 4.

Os resultados relativos às modalidades de inserção evidenciam que as proposições postularam, prioritariamente, que a Orientação Profissional fosse ofertada de forma obrigatória pelas escolas, mas facultativa ao aluno, como atividade extracurricular e gratuita, principalmente nas redes públicas de ensino. Quanto às atividades relativas à Orientação Profissional no contexto escolar, observou-se que a aplicação de testes e a informação a respeito de cursos e profissões constituíram com 50\% do total de atividades citadas nas proposições legislativas. Em geral, essas atividades apareceram quando da análise ou da justificativa da proposição, mas em $25 \%$ dos

Tabela 3

Níveis de ensino e público-alvo/série nas proposições legislativas no âmbito Federal

\begin{tabular}{|c|c|c|c|c|c|c|}
\hline \multirow{2}{*}{ NÍVEL DE ENSINO } & \multicolumn{2}{|c|}{ CONGRESSO } & \multicolumn{2}{|c|}{ SENADO } & \multicolumn{2}{|c|}{ TOTAL } \\
\hline & $\mathrm{F}$ & $\%$ & $\mathrm{~F}$ & $\%$ & $\mathrm{~F}$ & $\%$ \\
\hline - Educação Básica & 01 & 4,3 & 01 & 33,3 & 02 & 7,7 \\
\hline - EM - Regular & 11 & 47,9 & 02 & 66,7 & 13 & 50,0 \\
\hline - EM - último ano & 04 & 17,4 & -- & -- & 04 & 15,4 \\
\hline - EM - Técnico & 03 & 13,1 & -- & -- & 03 & 11,6 \\
\hline - Educação de Jovens e Adultos & 02 & 8,7 & -- & -- & 02 & 7,7 \\
\hline - Educação Superior & 01 & 4,3 & -- & -- & 01 & 3,8 \\
\hline - Não especifica nível & 01 & 4,3 & -- & -- & 01 & 3,8 \\
\hline TOTAL & 23 & 100 & 03 & 100 & 26 & 100,0 \\
\hline
\end{tabular}


Tabela 4

Modalidades de inserção e Atividades propostas para orientação profissional nas proposições legislativas

\begin{tabular}{|c|c|c|c|c|c|c|}
\hline \multirow{2}{*}{ MODALIDADE } & \multicolumn{2}{|c|}{ CÂMARA } & \multicolumn{2}{|c|}{ SENADO } & \multicolumn{2}{|c|}{ TOTAL } \\
\hline & $\mathrm{F} \%$ & $\mathrm{~F}$ & $\mathrm{~F} \%$ & $\mathrm{~F}$ & $\mathrm{~F} \%$ & \\
\hline Obrigatória (pela escola) & 05 & 17,8 & 01 & 25,0 & 06 & 18,7 \\
\hline Facultativo (ao aluno) & 05 & 17,8 & -- & & 05 & 15,6 \\
\hline Pública e privada & 04 & 14,3 & -- & & 04 & 12,5 \\
\hline Pública & 04 & 14,3 & -- & & 04 & 12,5 \\
\hline Pública e bolsista & 01 & 3,6 & 01 & 25,0 & 02 & 6,3 \\
\hline Extracurricular & 05 & 17,8 & -- & & 05 & 15,6 \\
\hline Disciplina & 01 & 3,6 & -- & & 01 & 3,1 \\
\hline Serviço de OP & 01 & 3,6 & 01 & 25,0 & 02 & 6,3 \\
\hline Não especifica & 02 & 7,2 & 01 & 25,0 & 03 & 9,4 \\
\hline TOTAL & 28 & 100,0 & 4 & 100,0 & 32 & 100,0 \\
\hline ATIVIDADES PROPOSTAS & $\mathrm{F}$ & $\mathrm{F} \%$ & $\mathrm{~F}$ & $\mathrm{~F} \%$ & $\mathrm{~F}$ & $\mathrm{~F} \%$ \\
\hline Aplicação de testes & 04 & 23,5 & 01 & 33,3 & 05 & 25,0 \\
\hline Informação Profissional & 05 & 29,4 & -- & -- & 05 & 25,0 \\
\hline Palestras & 01 & 5,9 & -- & -- & 01 & 5,0 \\
\hline Consultas e entrevistas & 01 & 5,9 & -- & -- & 01 & 5,0 \\
\hline $\begin{array}{l}\text { Associação de técnicas e instrumentais - autoconhecimento e } \\
\text { informações }\end{array}$ & 02 & 11,8 & -- & -- & 02 & 10,0 \\
\hline Atendimento interdisciplinar & 01 & 5,9 & -- & -- & 01 & 5,0 \\
\hline Não especifica & 03 & 17,6 & 02 & 66,7 & 05 & 25,0 \\
\hline TOTAL & 17 & 100,0 & 03 & 100,0 & 20 & 100,0 \\
\hline
\end{tabular}

projetos analisados foram citadas apenas atividades de Orientação Vocacional ou Orientação Profissional. Novamente o PL 426/2015 se diferencia ao propor um Serviço de Orientação Profissional especializado, centrado no processo, não restrito a testes vocacionais, embora ainda voltado para o apoio à tomada de decisão sobre prosseguimento de estudos em curso técnico de nível médio e na educação superior. A última categoria analisada, como se pode observar na Tabela 5 , refere-se aos profissionais encarregados pelo desenvolvimento das atividades.

O psicólogo e o pedagogo foram os profissionais mais citados, mas é importante observar que em várias proposições aparecem mais de um profissional. Assim, se forem contabilizadas as vezes que os profissionais foram citados sozinhos ou com outros profissionais, temos o psicólogo como o profissional mais citado (50\%), seguido do

Tabela 5

Profissionais encarregados da orientação profissional nas proposições legislativas

\begin{tabular}{|c|c|c|c|c|c|c|}
\hline \multirow{2}{*}{ PROFISSIONAIS } & \multicolumn{2}{|c|}{ CÂMARA } & \multicolumn{2}{|c|}{ SENADO } & \multicolumn{2}{|c|}{ TOTAL } \\
\hline & $\mathrm{F}$ & $\mathrm{F} \%$ & $\mathrm{~F}$ & $\mathrm{~F} \%$ & $\mathrm{~F}$ & $\mathrm{~F} \%$ \\
\hline Psicólogos & 03 & 21,4 & -- & -- & 03 & 17,6 \\
\hline Pedagogos & 02 & 14,3 & -- & -- & 02 & 11,8 \\
\hline Psicólogos e pedagogos & 02 & 14,3 & -- & -- & 02 & 11,8 \\
\hline Profissionais especializados & 02 & 14,3 & 01 & 33,3 & 03 & 17,6 \\
\hline Psicólogos, pedagogos ou profissionais especializados & 02 & 14,3 & -- & -- & 02 & 11,8 \\
\hline Não especifica & 03 & 21,4 & 02 & 66,7 & 05 & 29,4 \\
\hline TOTAL & 14 & 100 & 03 & 100,0 & 17 & 100,0 \\
\hline
\end{tabular}


pedagogo $(43 \%)$. As referências relativas a profissionais especializados independem da classe profissional abrangida, fazem menção a uma qualificação necessária para o exercício da função, tais como Habilitação em Orientação Educacional ou na área da Psicologia. Nesse sentido, a International Association for Education and Vocational Guidance (IAEVG) estabelece 11 competências-chave que o orientador profissional deve possuir, além das competências especializadas de acordo com a especificidade do trabalho realizado (Repetto, Talavera, Lévano, Soto, Ferrer-Sama, \& Hiebert, 2004).

A partir das diretrizes internacionais, integrantes da ABOP (Associação Brasileira de Orientação Profissional) desenvolveram uma proposta de diretrizes nacionais para a formação em Orientação Profissional, no sentido de estabelecer as competências básicas a serem desenvolvidas na formação dos orientadores profissionais brasileiros "guardadas as especificidades culturais e do sistema educacional brasileiro" (Lassance, Melo-Silva, Bardagi, \& Paradiso, 2007, p. 4). Para se obter uma certificação para o trabalho na área da Orientação Profissional, realizado em diferentes contextos e momentos de vida, a proposta centra-se em três conjuntos de competências, habilidades e conhecimentos: (1) formação teórica, (2) formação prática, e (3) desenvolvimento pessoal e ético. Os itens dos três conjuntos constituem recomendações gerais, pois considera-se que a diversidade tende a enriquecer o trabalho na área (Lassance et al., 2007).

Em relação à Orientação Profissional no contexto escolar, ainda não se tem um conjunto de competências ou de referências técnicas para orientar a formação ou a atuação de profissionais neste contexto específico. $\mathrm{O}$ trabalho de Munhoz, Melo-Silva e Audibert (2015) sobre Educação para a Carreira é uma relevante referência sobre o tema, oferecendo pistas para a atuação, mas ainda é preciso avançar muito. Para a proposição de PLs e/ou implantação da Lei recomenda-se a participação da Associação Brasileira de Orientação Profissional (ABOP), uma vez que essa associação reúne especialistas da área, no sentido de oferecer subsídios para formação e certificação aos profissionais que atuarão na área. E ao mesmo tempo, oferecer parâmetros e referências técnicas para a formação na área. Cabe à $\mathrm{ABOP}$ acompanhar as proposições, divulgar as informações junto aos especialistas e manifestar-se junto aos legisladores e à comunidade. E, também oferecer parâmetros e referências técnicas tanto para a formação na área quanto para a oferta de programas e serviços.

Nessa direção, a ABOP coordenou duas iniciativas com vistas às políticas públicas. A primeira, em 13 de julho de 2016, consistiu no contato pessoal com o Deputado Moses Rodrigues, relator do Projeto de Lei $\mathrm{n}^{\circ}$ 5053/2016, que acrescenta parágrafo único ao art. 22 da Lei no 9.394, de 20 de dezembro de 1996 (Lei de Diretrizes e Bases da Educação Nacional), para instituir a oferta de Serviço de Orientação Profissional especializado na educação básica e que foi aprovado no Senado Federal, em 14 de abril de 2016, sob a alcunha de PLS 426/2015, com base no excelente texto do relator Senador Donizeti Nogueira. A segunda inciativa foi formalmente realizada em 15 de outubro de 2016, quando a ABOP expressou o compromisso público, por meio de uma carta inédita enviada aos legisladores, apoiando o PL 5053/2016, originado do PLS 426/2015 e aprovado pelo Senado Federal, que propõe instituir a oferta de serviços de Orientação Profissional especializado na educação básica. A carta encontra-se disponível no site da ABOP (https://drive. google.com/file/d/1uBYeOa8XP0aVibH7n1PQlZ5f8rsfOLNj/view). O referido projeto representa um avanço importante em relação aos anteriores, pois apresenta-se em sintonia com a produção do conhecimento, apresentando viabilidade técnica e política.

\section{Considerações Finais}

Este estudo teve como objetivos identificar, sistematizar e analisar a legislação brasileira, as leis e as proposições legislativas, acerca da inserção da prática da Orientação Profissional no sistema educacional brasileiro. A partir dos resultados encontrados nas casas legislativas do Congresso Nacional observa-se que há interesse crescente dos legisladores em relação à inserção de atividades de Orientação Profissional nos sistemas educacionais do Brasil. Nesse sentido, aumenta a responsabilidade dos pesquisadores e profissionais do campo da Orientação Profissional em acompanhar o andamento destas iniciativas, no sentido de contribuir para que as políticas públicas a serem adotadas sejam respaldadas devidamente no conhecimento produzido a partir de pesquisas.

De modo geral, a análise da legislação permitiu constatar que a oferta de serviços de Orientação no contexto escolar, ao longo do tempo, foi pensada segundo três vertentes: Orientação Educacional, Orientação Vocacional e Orientação Profissional. A Orientação Educacional se caracterizou por ser oferecida nas escolas com vistas a auxiliar o indivíduo de modo integral, em relação ao processo ensino-aprendizagem. A Orientação Vocacional esteve voltada a ajudar os alunos quanto à escolha de um curso técnico ou superior. Como referido anteriormente, este termo traz em sua acepção a ideia de um indivíduo com inclinações ou disposição natural para determinada atividade, sendo o papel do orientador diagnosticar as características pessoais e ajustá-las a ocupações segundo o perfil profissional exigido. Nesse sentido, verifica-se a importância dos testes e inventários nos processos de Orientação Vocacional, no diagnóstico de características individuais, o que pode ter contribuído para o predomínio do termo nas proposições. Por sua vez, o conceito Orientação Profissional passa a ser utilizado, abarcando teorias 
e práticas de auxílio a pessoas nas decisões sobre estudos e/ou trabalho.

Concepções mais atuais, em especial a terminologia Educação para a Carreira não foram observadas nos documentos consultados. De acordo com a literatura essa é uma referência importante, pois é aplicável em todos os ciclos da educação e os programas podem ser realizados por psicólogos, educadores e profissionais de outras áreas, desde que capacitados. Entretanto, mesmo entre os estudiosos da área não há um consenso acerca de uma nomenclatura exclusiva para o contexto escolar. $\mathrm{O}$ termo Orientação Profissional é conhecido pela sociedade e pode permanecer nas proposições que se dirigem ao contexto escolar. Por sua vez, ressalta-se que os pressupostos da Educação para a Carreira são úteis aos profissionais e apropriados para subsidiar estudos e práticas que se destinam a oferecer Orientação Profissional no contexto educacional.

Em relação às proposições legislativas, os resultados demonstraram que a inserção de serviços de Orientação Profissional se destinaria prioritariamente para as escolas públicas. Com base na observação cotidiana dos autores, mesmo nas escolas particulares, quando acontecem atividades de Orientação Profissional elas se restringem a palestras sobre cursos e mercado de trabalho, o que se caracteriza como um item, o primeiro, que compõe a orientação -a Informação Profissional-, importante, mas insuficiente, como se defendeu neste estudo.

Neste sentido, observou-se que está em tramitação na Câmara dos Deputados um projeto de lei que, embora se restrinja a alunos de escolas públicas e beneficiários de bolsa integral de escolas particulares, apresenta na análise que antecede o voto uma argumentação consistente e atualizada para retirar do projeto inicial a oferta de "testesvocacional" e inserir a oferta de serviços de "Orientação Profissional". Importante reafirmar que este projeto foi aprovado pelo Senado Federal e enviado à Câmara dos Deputados para análise e apreciação do Plenário.

O que se verifica a partir dos resultados da análise das proposições legislativas, é que os legisladores são sensíveis para a temática em decorrência das velozes transformações na vida cotidiana e no mundo do trabalho e, também, das alterações na legislação, estabelecendo os percursos educacionais. Por outro lado, constata-se que ações relacionadas à Orientação Profissional não têm acontecido nas escolas brasileiras, públicas ou privadas. Quando ocorrem, são de forma pontual e não sistemática. Assim, não são observados avanços expressivos na legislação e menos ainda na prática.

Desta forma, aproximar os legisladores dos especialistas, e vice-versa, pode resultar em políticas públicas mais efetivas que poderão resultar em ações destinadas à preparação dos jovens para lidarem com os complexos desafios do século XXI. Qualquer política pública voltada para a Orientação Profissional precisa emergir no contexto das diretrizes para a educação. Assim, um caminho promissor para a Orientação Profissional contribuir com a educação básica seria via BNCC. Essa base define um conjunto de 10 competências gerais que devem ser desenvolvidas de forma integrada aos componentes curriculares, ao longo de toda a educação básica. Uma delas - Trabalho e projeto de vida- objetiva a valorização e a apropriação de conhecimentos e experiências para que o aluno possa entender o mundo do trabalho, fazer escolhas alinhadas à cidadania e a seu projeto de vida com liberdade e autonomia, criticidade e responsabilidade.

Para além da identificação de interesses e habilidades, de informações sobre o universo profissional e o mercado de trabalho, é fundamental considerar que, ao longo da escolarização, é importante ajudar os alunos a construírem seu projeto de vida e incorporarem os valores relativos ao trabalho e desenvolver competências-chave que serão utilizadas, no futuro, para o planejamento, o desenvolvimento e a progressão na carreira no século XXI, em um cenário configurado pelo desaparecimento de postos de trabalho, o surgimento de novas profissões e ocupações e os inúmeros desafios colocados ao trabalhador, entre eles resolver demandas complexas da vida cotidiana, do pleno exercício da cidadania e do mundo do trabalho.

\section{Referências}

Ambiel, R. A. M. (2010). Um estudo de caso em Orientação Profissional: Os papéis da avaliação psicológica e da informação profissional. Revista Brasileira de Orientação Profissional, 11(1), 133-143. Recuperado em 15 de maio de 2018, de http://pepsic.bvsalud.org/scielo.php?script=sci_arttext\&pid=S1679-33902010000100013\&lng=pt\&tlng= pt.

Brasil. Decreto-Lei $n^{\circ}$ 4.073. (1942a, 30 de janeiro). Lei Orgânica do Ensino Industrial. Presidência da República, Casa Civil, Subchefia para Assuntos Jurídicos, Brasília, DF, 1942a. Recuperado de http://www2.camara.leg.br/legin/fed/ declei/1940-1949/decreto-lei-4073-30-janeiro-1942-414503-publicacaooriginal-1-pe.html

Brasil. Decreto-Lei $n^{\circ}$. 4.244. (1942b, 9 de abril). Lei Orgânica do Ensino Secundário. Presidência da República, Casa Civil, Subchefia para Assuntos Jurídicos, Brasília, DF, 1942b. Recuperado de http://www2.camara.leg.br/legin/fed/ declei/1940-1949/decreto-lei-4244-9-abril-1942-414155-publicacaooriginal-1-pe.html. 
Brasil. Decreto-Lei $n^{\circ}$ 6.141. (1943, 28 de dezembro). Lei Orgânica do Ensino Comercial. Presidência da República, Casa Civil, Subchefia para Assuntos Jurídicos, Brasília, DF, 1943. Recuperado de http://www2.camara.leg.br/legin/fed/ declei/1940-1949/decreto-lei-6141-28-dezembro-1943-416183-publicacaooriginal-1-pe.html.

Brasil. Decreto-Lei $n^{\circ}$ 8.530. (1946a, 2 de janeiro). Lei Orgânica do Ensino Normal. Presidência da República, Casa Civil, Subchefia para Assuntos Jurídicos, Brasília, DF, 1946b. Recuperado de http://www2.camara.leg.br/legin/fed/ declei/1940-1949/decreto-lei-8530-2-janeiro-1946-458443-publicacaooriginal-1-pe.html.

Brasil. Decreto-Lei $n^{\circ} 9.613$ (1946b, 20 de agosto). Lei Orgânica do Ensino Agrícola. Presidência da República, Casa Civil, Subchefia para Assuntos Jurídicos, Brasília, DF, 1946c. Recuperado de http:/www2.camara.leg.br/legin/fed/ declei/1940-1949/decreto-lei-9613-20-agosto-1946-453681-publicacaooriginal-1-pe.html.

Brasil. Lei $n^{\circ}$ 4024. (1961, 20 de dezembro). Fixa as Diretrizes e Bases da Educação Nacional. Brasília, DF: Presidência da República. Recuperado de http://www2.camara.leg.br/legin/fed/lei/1960-1969/lei-4024-20-dezembro-1961-353722-normaatualizada-pl.pdf

Brasil. Lei ${ }^{\circ}$ 5692. (1971, 11 de agosto). Fixa Diretrizes e Bases para o ensino de $1^{\circ}$ e $2^{\circ}$ graus. Brasília, DF:Presidência da República. Recuperado dehttp://www2.camara.leg.br/legin/fed/lei/1970-1979/lei-5692-11-agosto-1971-357752-publicacaooriginal-1-pl.html

Brasil. Lei $n^{\circ}$ 7.044. (1982,18 de outubro). Altera dispositivos da Lei ${ }^{0}$ 5.692, de 11 de agosto de 1971, referentes a profissionalização do ensino de $2^{\circ}$ grau. Brasília, DF: Presidência da República. Recuperado de http://www2.camara. leg.br/legin/fed/lei/1980-1987/lei-7044-18-outubro-1982-357120-publicacaooriginal-1-pl.html

Brasil. Lei $n^{\circ}$ 9.394. (1996, 20 de dezembro). Estabelece as diretrizes e bases da educação nacional. Coleção de Leis da República Federativa o Brasil. Brasília. 188(12), 6419-6692, dez 1996. Recuperado de: file://C:/Users/Usuario/ Downloads/colecao_leis_1996.pdf

Brasil. Lei $n^{\circ}$ 11.741. (2008, 16 de julho). Altera dispositivos da Lei n ${ }^{\circ}$ 9.394, de 20 de dezembro de 1996. Brasília, DF: Presidência da República. Recuperado de https://www.planalto.gov.br/ccivil_03/_ato2007-2010/2008/lei/111741. htm

Brasil. Lei $n^{o}$ 13.005. (2014, 25 de junho). Aprova o Plano Nacional de Educação - PNE 2014-2024. Brasília, DF: Presidência da República. Recuperado de http:/www.planalto.gov.br/ccivil_03/_ato2011-2014/2014/lei/113005.htm

Brasil. Lei $n^{\circ}$ 13.415. (2017, 16 de fevereiro). Altera a Lei no 9.394, de 20 de dezembro de 1996. Brasília, DF: Presidência da República. Recuperado de http://www.planalto.gov.br/ccivil_03/_ato2015-2018/2017/Lei/L13415.htm

Brasil, MEC, SEB, DICEI (2013). Diretrizes Curriculares Nacionais Gerais da Educação Básica. Brasília: BRASIL. Recuperado de: http://portal.mec.gov.br/docman/julho-2013-pdf/13677-diretrizes-educacao-basica-2013-pdf/file

Brasil. MEC. SEB. CNE. (2017). Base Nacional Comum Curricular: Educação é a base. Recuperado de http://basenacionalcomum.mec.gov.br/abase/

Brasil. MEC. SEB.CNE. (2018). Base Nacional Comum Curricular: Educação é a base. Recuperado de http://basenacionalcomum.mec.gov.br/

Duarte, M. E. (2013). A vida da orientação na vida do século XXI: constrangimentos e desafios. Revista Brasileira de Orientação Profissional, 14(2), 155-164. Recuperado em 18 de fevereiro de 2017, de http://pepsic.bvsalud.org/scielo.php?script=sci_arttext\&pid=S1679-33902013000200002\&lng=pt\&tlng=pt.

Ferretti, C. J. (1997). Uma nova proposta de orientação profissional. São Paulo, 3.ed. SP: Cortez.

Guichard, J. (2012). Quais os desafios para o aconselhamento em orientação no início do século 21? Revista Brasileira de Orientação Profissional, 13(2), 139-152. Recuperado em 15 de fevereiro de 2017, de http://pepsic.bvsalud.org/ scielo.php?script=sci_arttext\&pid=S1679-33902012000200002\&lng=pt\&tlng=pt.

Hoyt, K. B. (2005). Career education as a federal legislative effort. In: HOYT, K. B. (Org.) Career education: history and future. Oklahoma: National Career Development Association, p. 3-74.

Hoyt, K. B.(1995). El concepto de educación para la carrera y sus perspectivas. In: Rodríguez, M. L. (Org.) Educación para la carrera y diseño curricular: teoría y práctica de programas de educación para el trabajo. Barcelona: Universitat de Barcelona, p. 15-37. 
Lamas, K. C. A. (2015). Estudos transversais e longitudinais de um instrumento de interesses profissionais. (Tese de doutorado). Recuperado de https://www.usf.edu.br/galeria/getImage/427/8208675191297204.pdf

Lassance, M. C. P.; Melo-Silva, L. L., Bardagi, M. P. \& Paradiso, A. C. (2007). Competências do orientador profissional: uma proposta brasileira com vistas à formação e certificação. Revista Brasileira de Orientação Profissional, 8(1), 87-94. Recuperado em 24 de maio de 2018, de http://pepsic.bvsalud.org/scielo. php?script $=$ sci_arttext\&pid $=$ S1679-33902007000100008\&lng=pt\&tlng=pt.

McCarthy, J. (2009). Desenvolvimento de políticas de orientação nas áreas de educação, formação e emprego na União Europeia. Revista Brasileira de Orientação Profissional, 10(1), 103-109. Recuperado em 24 de fevereiro de 2017, de http://pepsic.bvsalud.org/scielo.php?script=sci_arttext\&pid=S1679-33902009000100012\&lng=pt\&tlng=pt.

Melo-Silva, L., Lassance, M. C. P., \& Soares, D. H. P. (2004). A orientação profissional no contexto da educação e trabalho. Revista Brasileira de Orientação Profissional,4(2), 31-52. Recuperado em 24 de fevereiro de 2017, de http:// pepsic.bvsalud.org/scielo.php?script=sci_arttext\&pid=S1679-33902004000200005\&lng=pt\&tlng=pt.

Munhoz, I. M. S. (2010). Educação para a carreira e representações sociais de professores: Limites e possibilidades na educação básica (Tese de doutorado). Recuperado de http://www.teses.usp.br/teses/disponiveis/59/59137/tde18112010-200456/pt-br.php

Munhoz, I. M. S., \& Melo-Silva, L. L. (2012). Preparação para o trabalho na legislação educacional brasileira e educação para carreira. Psicologia Escolar e Educacional, 16(2), 291-298. Recuperado em 24 de fevereiro de 2017, de http:// www.scielo.br/pdf/pee/v16n2/a12v16n2.pdf

Munhoz, I. M. S., Melo-Silva, L. L., \& Silveira, A. A. (2015). Educação para a carreira: Pistas para intervenções na educação básica. In R. S. Levenfus (Org.), Orientação vocacional e de carreira em contextos clínicos e educativos (pp. 41-63). Porto Alegre, RS: Artmed.

Nascimento, M. N. M. (2007). Ensino médio no Brasil: determinações históricas. Publicatio, n.15, v.1, p: 77-87. Recuperado de: http://www.revistas2.uepg.br/index.php/humanas/article/view/594/581

Pimenta, S. G. (1981). Orientação vocacional e decisão:Estudo crítico da situação no Brasil (2a ed.). São Paulo, SP: Loyola.

Repetto Talavera, E., Lévano, B. M., Soto, N. M., Ferrer-Sama, P., \& Hiebert, B. (2004). Competências internacionais para orientadores profissionais. Revista Brasileira de Orientação Profissional, 5(1), 1-14. Recuperado em 24 de fevereiro de 2017, de http://pepsic.bvsalud.org/scielo.php?script=sci_arttext\&pid=S1679-33902004000100002\&ln $\mathrm{g}=\mathrm{pt} \&$ tlng $=\mathrm{pt}$.

Ribeiro, M. A. (2011). Orientação profissional: Uma proposta de guia terminológico. In M. A. Ribeiro \& L. L. Melo-Silva (Orgs.), Compêndio de orientação profissional e de carreira: Perspectivas históricas e enfoques teóricos clássicos e modernos. (Vol. 1, pp. 23-66). São Paulo, SP: Vetor.

Savickas, M. L., Nota, L., Rossier, J., Dauwalder, J.-P., Duarte, M. E., Guichard, J., Soresi, S., Van Esbroeck, R., \& van Vianen, A. E. M. (2010). A construção da vida: Um novo paradigma para compreender a carreira no século XXI. Revista Portuguesa de Psicologia, 42, 13-44. Recuperado de https://docs.google.com/file/d/0B0LP1bS3g1 daeUk1MGdsakFnX0U/ edit.

Recebido: 10/05/17 Aceito: 05/12/18 
APÊNDICE 1

Denominação dos documentos e sítios de busca das proposições legislativas

\begin{tabular}{ll}
\hline DENOMINAÇÃO & SÍTIOS \\
\hline INC 495/2007 & http://www.camara.gov.br/proposicoesWeb/fichadetramitacao?idProposicao=353434 \\
INC 1696/2015 & http://www.camara.gov.br/proposicoesWeb/fichadetramitacao?idProposicao=2071728) \\
EMC 336/2011 & http://www.camara.gov.br/proposicoesWeb/fichadetramitacao?idProposicao=504030 \\
MP 746/ 2016 & http://www.camara.gov.br/proposicoesWeb/fichadetramitacao?idProposicao=2112490 \\
PL 1275/2015 & http://www.camara.gov.br/proposicoesWeb/fichadetramitacao?idProposicao=1215574 \\
PL 2238/2007 & $\mathrm{http://www.camara.gov.br/proposicoesWeb/fichadetramitacao?idProposicao=372463}$ \\
PL 3303/2015 & $\mathrm{http} / /$ www.camara.gov.br/proposicoesWeb/fichadetramitacao?idProposicao=2017902 \\
PL 3993/2008 & $\mathrm{http://www.camara.gov.br/proposicoesWeb/fichadetramitacao?idProposicao=408789}$ \\
PL 4209/2015 & $\mathrm{http://www.camara.gov.br/proposicoesWeb/fichadetramitacao?idProposicao=2076073}$ \\
PL 4836/2009 & $\mathrm{http://www.camara.gov.br/proposicoesWeb/fichadetramitacao?idProposicao=426266}$ \\
PL 5053/2016 & $\mathrm{http://www.camara.gov.br/proposicoesWeb/fichadetramitacao?idProposicao=2082289}$ \\
PL 0562/2015 & $\mathrm{http://www.camara.gov.br/proposicoesWeb/fichadetramitacao?idProposicao=961613}$ \\
PL 6063/2013 & $\mathrm{http://www.camara.gov.br/proposicoesWeb/fichadetramitacao?idProposicao=586486}$ \\
PL 6068/2009 & $\mathrm{http://www.camara.gov.br/proposicoesWeb/fichadetramitacao?idProposicao=450668}$ \\
PL 6214/2013 & $\mathrm{http://www.camara.gov.br/proposicoesWeb/fichadetramitacao?idProposicao=589672}$ \\
PL 6510/2013 & $\mathrm{http://www.camara.gov.br/proposicoesWeb/fichadetramitacao?idProposicao=595271}$ \\
PL 6840/2013 & $\mathrm{http://www.camara.gov.br/proposicoesWeb/fichadetramitacao?idProposicao=602570}$ \\
PL 8035/2010 & $\mathrm{http://www.camara.gov.br/proposicoesWeb/fichadetramitacao?idProposicao=490116}$ \\
PL 0831/2015 & $\mathrm{http://www.camara.gov.br/proposicoesWeb/fichadetramitacao?idProposicao=1049308}$ \\
PL 0838/ 2007 & $\mathrm{http://www.camara.gov.br/proposicoesWeb/fichadetramitacao?idProposicao=349361}$ \\
PLS 187/2008 & $\mathrm{https://www25.senado.leg.br/web/atividade/materias/-/materia/85097}$ \\
PLS 228/2012 & $\mathrm{https://www25.senado.leg.br/web/atividade/materias/-/materia/106337}$ \\
PLS 426/2015 & $\mathrm{https://www25.senado.leg.br/web/atividade/materias/-/materia/122104}$
\end{tabular}


Sobre as autoras:

Lucy Leal Melo-Silva é psicóloga, docente sênior da Faculdade de Filosofia, Ciências e Letras de Ribeirão Preto, da Universidade de São Paulo. Investiga e orienta na Pós-Graduação em Psicologia no domínio da Orientação Profissional e de Carreira. Coordenadora do Carreira Lab. Coeditora da RBOP.

E-mail: lucileal@ffclrp.usp.br

Izildinha Maria da Silva Munhoz é psicóloga clínica e educacional, graduada e Doutora pela Faculdade de Filosofia, Ciências e Letras de Ribeirão Preto, da Universidade de São Paulo. Investigadora no domínio da Educação para a Carreira. E-mail: nimunhoz@terra.com.br

Mara de Souza Leal é psicóloga, graduada pela Universidade Federal de Uberlândia, Mestre e Doutoranda pela Faculdade de Filosofia, Ciências e Letras de Ribeirão Preto, da Universidade de São Paulo. Pesquisa desenvolvimento de carreira e competências socioemocionais.

E-mail: marasleal@usp.br 